\title{
Comparison of Umbilical Cord Serum Vitamin D Levels between Infants with Transient Tachypnea of the Newborn and those without Respiratory Distress
}

\author{
Hassan Boskabadi, MD¹; Gholamali Maamouri, MD¹; Farnaz Kalani-moghaddam, MD²; Mohammad Hosein Ataee Nakhaei, MD²; Maryam \\ Zakerihamidi, $\mathrm{MD}^{3}$; Forough Rakhshanizadeh, $\mathrm{MD}^{4^{*}}$

\begin{abstract}
${ }^{1}$ Department of Pediatrics, Neonatal Research Centre, Faculty of Medicine, Mashhad University of Medical Sciences, Mashhad, Iran ${ }^{2}$ Department of pediatrics, Faculty of Medicine, Mashhad University of Medical Sciences, Mashhad, Iran ${ }^{3}$ Department of Midwifery, Faculty of Medicine, Islamic Azad University, Tonekabon Branch, Tonekabon, Iran ${ }^{4}$ Department of Pediatrics, Faculty of Medicine, Mashhad University of Medical Sciences, Mashhad, Iran
\end{abstract}

\begin{abstract}
Background: Transient tachypnea of the newborn (TTN) is one of the most frequent causes of respiratory distress in neonates. A relationship has been shown between vitamin D deficiency and respiratory disorders in neonates. This research was carried out to evaluate the serum level of vitamin D in TTN newborns and their mothers compared to the control group.

Methods: This case-control research was conducted during 2016-2019 in a general hospital affiliated with Mashhad University of Medical Sciences, Iran. Thirty-four infants with TTN and 82 neonates in the control group as well as their mothers were investigated. The levels of umbilical cord serum vitamin D in infants with TTN and also their mothers were compared to the control group.

Results: The mean levels of serum vitamin D in infants with TTN and their mothers were $8.11 \pm 4.32$ and $12.6 \pm 10.12 \mathrm{ng} / \mathrm{mL}$, respectively $(P<0.001)$, whereas they were $19.21 \pm 12.71$ and $25.96 \pm 16.6 \mathrm{ng} / \mathrm{mL}$ in the newborns of the control group and their mothers, respectively $(P<0.001)$. The mean differences $(95 \% \mathrm{Cl})$ of neonatal and maternal vitamin $\mathrm{D}$ level between the two groups were 11.10 (7.92-14.28) and 13.36 (7.90-18.08), respectively. In the TTN group, 100\% of the infants had vitamin D levels less than $30 \mathrm{ng} / \mathrm{mL}$ (79.4\% had severe, $17.6 \%$ had moderate and $2.9 \%$ showed mild deficiency). However, vitamin D levels lower than $30 \mathrm{ng} / \mathrm{mL}$ were observed in $76.4 \%$ of the neonates in the control group $(28.8 \%$ had severe, $31.1 \%$ showed moderate and $16.3 \%$ had a mild deficiency) $(P<0.001)$

Conclusion: The serum vitamin D levels of infants with TTN and their mothers were significantly lower than the control group. Therefore, TTN in infants may be reduced through the treatment of vitamin D deficiency in mothers. Keywords: Newborn, Respiratory distress, Transient tachypnea of the newborn, Vitamin D deficiency

Cite this article as: Boskabadi H, Maamouri G, Kalani-moghaddam F, Ataee Nakhaei MH, Zakerihamidi M, Rakhshanizadeh F. Comparison of umbilical cord serum vitamin D levels between infants with transient tachypnea of the newborn and those without respiratory distress. Arch Iran Med. 2020;23(8):530-535. doi: 10.34172/aim.2020.55.
\end{abstract}

Received: August 18, 2019, Accepted: June 2, 2020, ePublished: August 1, 2020

\section{Introduction}

Transient tachypnea of the newborn (TTN) is one of the most frequent causes of respiratory distress in neonates, which involves 3.6 to 5.7 infants per 1000 term newborns. The onset of tachypnea or the evidence of respiratory distress is regarded as clinical manifestations of TTN. Such presentations can be seen within the first hours of life and resolve spontaneously within 72 hours with no need for any intervention; however, serious complications are possible in some cases. ${ }^{1} \mathrm{TTN}$ results from delayed postnatal clearance of fetal lung fluid. The passive transport of sodium through the epithelial sodium channels (ENaCs) in type II pneumocytes is the accepted mechanism for fetal lung fluid clearance. Following adrenergic stimulation before labor and epinephrine release, $\mathrm{ENaC}$ is activated and calcium ions may act as a secondary intracellular messenger in this process. When sodium enters type II pneumocytes through the $\mathrm{ENaC}$ channel, it migrates toward the interstitial space via the basolateral $\mathrm{Na} / \mathrm{K}$ ATPase, resulting in water and chlorine passive efflux. ${ }^{2-4}$ Immaturity of the ENaCs is considered as the main reason for the failure of lung fluid reabsorption., ${ }^{5,6}$ Although the pathophysiology of TTN is basically associated with delayed clearance of lung fluid, mild insufficiency of the surfactant system has been shown to reduce the amount of surfactant and/or its function. Therefore, TTN may be a multifactorial disease caused by delayed clearance of lung fluid and varying degrees of surfactant abnormalities.

TTN is known to be associated with certain risk factors, including cesarean delivery, male gender, history of asthma or diabetes mellitus in the mother, macrosomia, and late preterm birth. ${ }^{1,8}$ Recently, the correlation between TTN 
and maternal and neonatal vitamin D deficiency has been indicated in two studies. ${ }^{9,10}$

Vitamin D is a steroid hormone which is essential for the balance of minerals, bone metabolism, and neuromuscular function. In recent years, due to the identification of vitamin $\mathrm{D}$ receptors in different cells of the body, other effects of this vitamin have been identified increasingly. Several studies have demonstrated that vitamin D plays a vital role in regulation of more than 1000 genes involved in many biological processes, including angiogenesis, inflammation, and immune function. ${ }^{11,12}$ It has been also shown that it is crucial to the development of fetal lung via different mechanisms, such as surfactant metabolism, epithelial-mesenchymal interactions, and calcium regulation in type II pneumocytes. ${ }^{13-15}$

The maternal vitamin $\mathrm{D}$ level is a determinant factor for its concentration in the fetus and infant. ${ }^{16}$ Vitamin D deficiency has been widely reported throughout pregnancy and is associated with increased risk of poor fetal growth, ${ }^{17}$ neonatal sepsis, ${ }^{18}$ and higher rate of respiratory tract infections. ${ }^{19}$ Respiratory distress syndrome (RDS), retinopathy of prematurity (ROP) and cerebral hemorrhage are other common newborn problems in which vitamin D is involved. ${ }^{20,21}$ The relationship between vitamin D and TTN has not been studied widely; accordingly, this research was done to evaluate the serum levels of vitamin $\mathrm{D}$ in TTN newborns and also their mothers and compare them to a control group.

\section{Materials and Methods}

This case-control research was conducted during 20162019 in a general hospital affiliated with Mashhad University of Medical Sciences, Iran. The sample size was estimated at 34 patients, based on a study by Singh et al. ${ }^{22}$ through two independent samples formula in infants with TTN (Mean \pm SD: $11.32 \pm 8.2$ ) and infants without respiratory distress $(22.66 \pm 13.15)$, type I error (alpha) of $1 \%$, and power (beta) of $90 \%$. All preterm neonate (gestational age $<37$ weeks) born in this time period and their mothers were entered to the study consecutively. The following potential confounders were considered as the exclusion criteria: apparent congenital anomalies, congenital infections, severe asphyxia, cardiopulmonary resuscitation in the delivery room, infants with respiratory distress who did not meet the TTN criteria, and history of maternal substance abuse, diabetes or asthma. Those diagnosed with TTN and also their mothers were assigned to the case group. The control group included infants who did not meet the TTN criteria and had no respiratory distress, alongside their mothers. TTN was diagnosed in the infants based on the presence of clinical conditions (tachypnea/retraction of the accessory muscles of respiration/ grunting/ nasal flaring) through the first hours of birth lasting for more than 12 hours and resolving spontaneously within 48-72 hours. The changes observed in chest X-ray images included perihilar streaking, fluid in the interlobar fissure, hyperinflation and flattening of the diaphragm, and other causes of respiratory distress (such as pneumonia, RDS and pneumothorax) were ruled out. ${ }^{1}$

A researcher-made checklist was used to collect the demographic information of neonates and their mothers, such as delivery method, birth weight, maternal age, gestational age, gender, underlying maternal-related conditions (high blood pressure, asthma, diabetes, etc), pregnancy-related complications, parity, a history of respiratory problems in siblings, a history of vitamin $\mathrm{D}$ supplementation during pregnancy, first- and fifth-minute Apgar score, clinical signs of the infant on admission (tachypnea, retraction of the accessory muscles of respiration, nasal flaring, grunting and hypoxia), need for resuscitation and ventilation, duration of oxygen therapy and duration of hospitalization in the neonatal intensive care unit (NICU).

From the infants, $1.5 \mathrm{~mL}$ of whole blood was collected from the umbilical cord to measure vitamin $\mathrm{D}$ levels. Blood samples were also taken from mothers for the same purpose. Samples were centrifuged and the collected serum samples were stored at $-20^{\circ} \mathrm{C}$ and sent to the laboratory for further analysis. The enzyme-linked immunosorbent assay (ELISA) through ELISA Reader (model RT2100c, Germany) was employed to evaluate the serum levels of 25-hydroxyvitamin D. A vitamin D level of less than 30 $\mathrm{ng} / \mathrm{mL}$ was considered as vitamin $\mathrm{D}$ deficiency. Levels less than $10 \mathrm{ng} / \mathrm{mL}$ were considered as severe, 10 to $20 \mathrm{ng} / \mathrm{mL}$ as moderate and 20 to $30 \mathrm{ng} / \mathrm{mL}$ as mild deficiency. ${ }^{23}$

After collecting data and entering data into SPSS version 23, tables, figures, and statistical indices were used to analyze the results and evaluate the relationship between variables. For this purpose, after checking the normal distribution of data, Pearson's correlation coefficient and independent $t$ test were used for normally distributed data. For non-normally distributed data, non-parametric statistics, including the Mann-Whitney coefficient was used. To analyze the relationship between variables and nominal scale, the Chi-square test was used. In the current study, $P$ values less than 0.05 were considered significant.

\section{Results}

Thirty-four neonates with TTN and 82 neonates as the control group were evaluated. In the TTN group, 35.3\% of the subjects were male and $64.7 \%$ were female, whereas in the control group, $44.9 \%$ were male and $55.1 \%$ were female. No significant difference was observed between the two groups in delivery method, maternal age, gestational age, birth weight, first- and fifth-minute Apgar score, underlying maternal conditions, and pregnancyrelated complications $(P>0.05$; Table 1$)$. Blood cultures were negative for all subjects and there was no evidence of intra-ventricular hemorrhage on ultrasound imaging of the brain. 
Table 1. Demographic Characteristics of the Study and Control Groups

\begin{tabular}{|c|c|c|c|c|c|}
\hline \multirow{2}{*}{ Variable } & & Control Group & TTN Group & Mean Difference & \multirow{2}{*}{$P$ value } \\
\hline & & Mean \pm SD $/$ No. $(\%)$ & Mean \pm SD/No. $(\%)$ & $95 \%(\mathrm{Cl})$ & \\
\hline \multicolumn{2}{|l|}{ Gestational age (wk) } & $32.64 \pm 1.76$ & $32.26 \pm 1.56$ & $0.381(-0.309-1.072)$ & 0.27 \\
\hline \multicolumn{2}{|l|}{ Apgar at first minute } & $7.53 \pm 1.51$ & $7.01 \pm 1.52$ & $0.59(-0.08-1.267)$ & 0.09 \\
\hline \multicolumn{2}{|l|}{ Apgar at fifth minute } & $8.68 \pm 1.12$ & $8.44 \pm 1.05$ & $0.242(-0.195-0.678)$ & 0.28 \\
\hline \multicolumn{2}{|l|}{ Weight (g) } & $1535.4 \pm 351.07$ & $1606.61 \pm 256.12$ & $-71.21(-187.7-45.29)$ & 0.22 \\
\hline \multicolumn{2}{|l|}{ Maternal age (y) } & $28.04 \pm 6.4$ & $28.32 \pm 6.45$ & $-0.279(-2.956-2.397)$ & 0.83 \\
\hline \multirow{2}{*}{ Sex } & Male & $35(44.9 \%)$ & $12(35.3 \%)$ & & \multirow{2}{*}{0.34} \\
\hline & Female & $43(55.1 \%)$ & $22(64.7 \%)$ & & \\
\hline \multirow{2}{*}{ Pregnancy complications } & Yes & $41(50 \%)$ & $21(72.7 \%)$ & & \multirow{2}{*}{0.21} \\
\hline & No & $41(50 \%)$ & $8(27.3 \%)$ & & \\
\hline \multirow{2}{*}{ Type of delivery } & NVD & $49(60.3 \%)$ & $26(\% 76.2)$ & & \multirow{2}{*}{0.16} \\
\hline & CS & $32(39.7 \%)$ & $8(23.8 \%)$ & & \\
\hline
\end{tabular}

NVD, natural vaginal delivery; CS, cesarean section.

The average serum vitamin D level was $12.6 \pm 10.12$ and $25.95 \pm 16.6 \mathrm{ng} / \mathrm{mL}$ in mothers in the TTN and control groups, respectively. In addition, the mean serum vitamin $\mathrm{D}$ level in neonates of the TTN group was $8.11 \pm 4.32 \mathrm{ng} /$ $\mathrm{mL}$, whereas it was $19.21 \pm 12.71 \mathrm{ng} / \mathrm{mL}$ in neonates of the control group (Table 2 and Figure 1).

In general, $69.5 \%$ of the mothers had vitamin $\mathrm{D}$ levels of less than $30 \mathrm{ng} / \mathrm{mL}$ (32.6\% had severe, $29.5 \%$ had moderate, and $7.4 \%$ had mild deficiency). Among the infants, $83.4 \%$ showed vitamin D levels of less than $30 \mathrm{ng} /$ $\mathrm{mL}$ (43.9\% had severe, $27.2 \%$ had moderate, and $12.3 \%$ showed mild deficiency).

In the TTN group, $56 \%$ of the mothers showed severe and $27 \%$ showed moderate vitamin D deficiency, whereas it was $20 \%$ and $31 \%$ in mothers of the control group, respectively $(P=0.002)$. In the TTN group, $100 \%$ of the infants had vitamin D levels of less than $30 \mathrm{ng} / \mathrm{ml}(79.4 \%$ had severe, $17.6 \%$ had moderate and $2.9 \%$ showed mild deficiency). However, vitamin D levels of lower than 30 $\mathrm{ng} / \mathrm{mL}$ were observed in $76.4 \%$ of the neonates in the control group (28.8\% had severe, $31.1 \%$ showed moderate and $16.3 \%$ had mild deficiency), whereas $23.8 \%$ of them had normal levels $(P<0.05)$ (Table 3 and Figure 1 ).

\section{Discussion}

According to the results, about three quarters of the mothers and four fifths of the newborns had vitamin $D$ deficiency, of whom $62 \%$ of the mothers and $71 \%$ of the infants showed significant (moderate and severe) vitamin $\mathrm{D}$ deficiency. The incidence of vitamin $\mathrm{D}$ deficiency has been reported at $30 \%$ to $88 \%$ in infants as well as mothers worldwide. ${ }^{20-26}$ In a study in Iran, 552 mothers and infants were examined for serum vitamin D levels and the results showed that $66 \%$ of the mothers and $93 \%$ of the newborns had vitamin D deficiency. ${ }^{27}$ Our findings demonstrated a high prevalence of vitamin $\mathrm{D}$ deficiency among Iranian mothers and newborns, which is consistent with the mentioned study. Accordingly, prevention and timely diagnosis of this concern should be considered. Several factors can be involved in the high incidence of vitamin $\mathrm{D}$ deficiency in the studied subjects, including lack of exposure to the sun, low maternal vitamin D intake (seafood, such as fish and shrimp) and prematurity in infants.

Vitamin D levels were significantly lower in mothers and infants in the TTN group compared to the control group. In fact, vitamin $\mathrm{D}$ levels were nearly 2.5 times greater in the infants without TTN as well as their mothers in

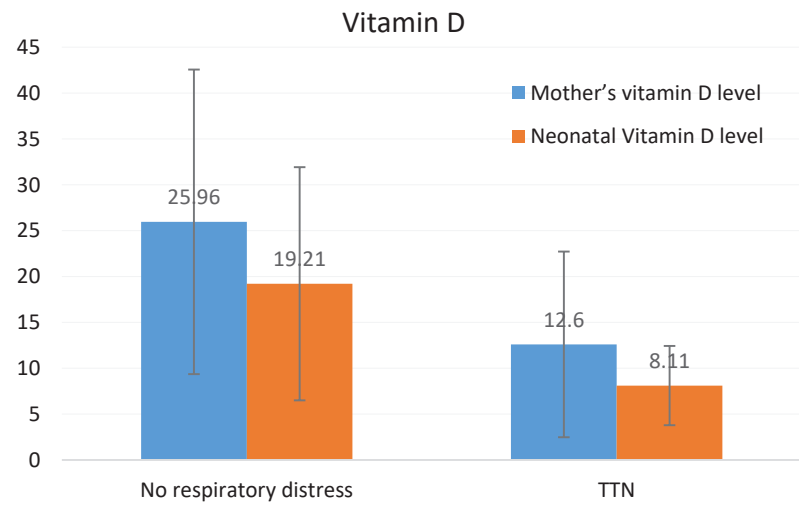

Figure 1. Comparison of Vitamin D Serum Levels between the Cases and the Controls.

Table 2. Mean and Standard Deviation of 25OHD Serum Level in the Neonates and the Mothers of Both Group

\begin{tabular}{|c|c|c|c|c|c|}
\hline \multirow{2}{*}{ Variable } & \multirow{2}{*}{ Total } & Control Group & TTN Group & \multirow{2}{*}{ Mean Difference $(95 \% \mathrm{CI})$} & \multirow{2}{*}{$P$ Value } \\
\hline & & Mean \pm SD & Mean \pm SD & & \\
\hline Maternal vitamin D level & 95 & $25.96 \pm 16.6$ & $12.6 \pm 10.12$ & $13.36(7.9-18.08)$ & $<0.001$ \\
\hline Neonatal vitamin D level & 114 & $19.21 \pm 12.71$ & $8.11 \pm 4.32$ & $11.1(7.92-14.28)$ & $<0.001$ \\
\hline
\end{tabular}


Table 3. Serum Levels of 25OHD in the Neonates and the Mothers of Both Group

\begin{tabular}{|c|c|c|c|c|}
\hline Variable & & $\begin{array}{c}\text { Control Group } \\
\text { No. }(\%) \\
\end{array}$ & $\begin{array}{c}\text { TTN Group } \\
\text { No. }(\%)\end{array}$ & Test Results \\
\hline \multirow{4}{*}{$\begin{array}{l}\text { Maternal vitamin D } \\
\text { level }(n=95)\end{array}$} & Severe vitamin D deficiency & $12(19.7)$ & $19(55.9)$ & \multirow{4}{*}{$\begin{array}{c}\chi^{2}=14.68 \\
P \text { value }=0.001\end{array}$} \\
\hline & Moderate vitamin D deficiency & $19(31.1)$ & $9(26.5)$ & \\
\hline & Mild vitamin D deficiency & $6(9.8)$ & $1(2.9)$ & \\
\hline & Normal vitamin D level & $24(39.3)$ & $5(14.7)$ & \\
\hline \multirow{4}{*}{$\begin{array}{l}\text { Neonatal vitamin } D \\
\text { level }(n=114)\end{array}$} & Severe vitamin D deficiency & $23(28.8)$ & $27(79.4)$ & \multirow{4}{*}{$\begin{array}{c}\chi^{2}=14.68 \\
P \text { value }<0.001\end{array}$} \\
\hline & Moderate vitamin D deficiency & $25(31.3)$ & $6(17.6)$ & \\
\hline & Mild vitamin D deficiency & $13(16.3)$ & $1(2.9)$ & \\
\hline & Normal vitamin D level & $19(23.8)$ & $0(0.0)$ & \\
\hline
\end{tabular}

Severe vitamin D deficiency: the level of less than $10 \mathrm{ng} / \mathrm{mL}$; Moderate vitamin D deficiency: 10 to $20 \mathrm{ng} / \mathrm{mL}$; Mild vitamin D deficiency: 20 to $30 \mathrm{ng} / \mathrm{mL}$; Normal vitamin D level: more than $30 \mathrm{ng} / \mathrm{mL}$.

comparison to the other group $(P<0.001)$. Nearly $80 \%$ of the mothers in the TTN group had severe or moderate vitamin $\mathrm{D}$ deficiency, whereas it was $50 \%$ among mothers in the control group $(P=0.002)$. Moreover, moderate or severe vitamin D deficiency was observed in $97 \%$ of the newborns in the TTN group; however, $60 \%$ of the infants in the control group were suffering from moderate or severe vitamin $\mathrm{D}$ deficiency $(P<0.05)$. Fifty-one newborns with TTN and 59 healthy infants were evaluated for the level of vitamin D deficiency by Konca et al. They demonstrated that the average level of vitamin $\mathrm{D}$ was 5.8 $\pm 3.5 \mathrm{ng} / \mathrm{mL}$ and $8.7 \pm 4.0 \mathrm{ng} / \mathrm{mL}$ in the newborns in the case and control groups, respectively $(P<0.01)$. They also concluded that lower serum vitamin $\mathrm{D}$ levels may be involved in TTN pathogenesis. Regarding the possible mechanism of this correlation, they noted that vitamin $\mathrm{D}$ deficiency may reduce the expression of $\mathrm{ENaC}$ and the synthesis of surfactants, which leads to TTN incidence. ${ }^{9}$ Thirty infants with TTN and their mothers were studied for vitamin D deficiency by Omran et al. They compared the results with the control group and reported that there was a significant difference in vitamin $\mathrm{D}$ level between the two groups; vitamin D levels in the TTN infants and their mothers were $7.74 \pm 3.17$ and $15.05 \pm 4.71 \mathrm{ng} /$ $\mathrm{mL}$, respectively, whereas in the control group, they were $16.08 \pm 5.41$ and $29.08 \pm 5.41 \mathrm{ng} / \mathrm{mL}$, respectively $(P$ $<0.0001)$. They concluded that TTN can be linked to low blood levels of vitamin D. ${ }^{10}$ Our findings indicating a correlation between vitamin D deficiency and TTN in newborns are consistent with the results obtained by these investigations.

The vital role of vitamin D in pulmonary maturation has been shown in recent animal studies. ${ }^{28,29}$ They have explained that the structure and performance of the lungs can be affected by its deficiency in the fetus and the neonate. ${ }^{30} \mathrm{~A}$ study by Nguyen et al in a rat model showed that 1,25-dihydroxycholecalciferol, by activation of 1,6-bisphosphatase fructose and the gluconeogenesis pathway, reduces the glycogen content of cells and disrupts the synthesis and secretion of surfactants. So, lung maturity can be influenced by vitamin $\mathrm{D}$ levels. ${ }^{14}$ The mechanisms by which vitamin $\mathrm{D}$ can affect fetal lung development were studied by Chen et al in a rat model. They reported that deficiency of vitamin $\mathrm{D}$ interferes with the structure and function of the lung by disrupting the production of surfactants, impairing the response to oxidative stress, and affecting the synthesis of collagen at the time of alveoli formation. ${ }^{15}$

The correlation between vitamin D deficiency and neonatal respiratory diseases has been considered in recent human studies, such as RDS as well as lower respiratory tract infection (LRTI). In this regard, it has been indicated that there is a correlation between vitamin D deficiency and increased risk of respiratory complications in mothers and newborns. ${ }^{31,32}$ Dinlen et al studied the serum level of vitamin D in 30 neonates with LRTI and 30 healthy newborns admitted to the NICU. They showed that LRTI was correlated with vitamin D deficiency. They suggested that supplementing pregnant women with vitamin $\mathrm{D}$ and also supplementing through early childhood can be effective in respiratory system function in infants. ${ }^{31}$ Another study was done on blood levels of vitamin D in 160 preterm neonates of less than 34 weeks' gestation with RDS and their mothers. The findings indicated that vitamin D levels in the case group were significantly less than the control group, indicating a significant association between vitamin $\mathrm{D}$ blood levels and RDS. ${ }^{21}$

Due to the limited numbers of studies on the relationship between vitamin D deficiency and TTN, the underlying mechanisms involved in this correlation have not been completely understood. The main cause of TTN is delayed lung fluid absorption at the time of birth, although studies have shown the decreased level of surfactants or their dysfunction. Due to the influence of vitamin $\mathrm{D}$ in lung function and maturation, its deficiency may affect the function of $\mathrm{ENaC}$ and reduce lung fluid reabsorption at birth. On the other hand, by affecting type II pneumocytes, the deficiency may also influence the synthesis and secretion of surfactants and ultimately, contribute to the incidence of TTN or other respiratory problems in infants. Such mechanisms can be suggested to explain the link between vitamin D deficiency and TTN 
in newborns; however, further investigations should be conducted for confirmation or rejection.

Further studies with larger sample sizes may result in a better understanding of this association. The effectiveness of supplementing with vitamin D during pregnancy and also its preventive role against development of TTN was not evaluated in our research. No study has been yet done on the effect of vitamin D deficiency in the clinical progression and severity of TTN, which indicates the need for further studies in the future.

In conclusion, vitamin $\mathrm{D}$ in infants is not only effective in bone metabolism but also in various systems in the body, such as the respiratory system. There is a positive correlation between maternal and neonatal vitamin D deficiency; therefore, its deficiency in the mother can affect the neonate, as well. Based on our findings, the TTN group showed a significantly lower level of vitamin D than the control group. Nearly all TTN infants and fourth fifths of their mothers were suffering from severe and moderate deficiency. These findings emphasize the importance of vitamin $\mathrm{D}$ for lung maturation and function and it can be concluded that vitamin $\mathrm{D}$ deficiency may be involved in the prevalence of TTN. Accordingly, it seems that accurate management of vitamin D during pregnancy can possibly reduce the risk of TTN in infants.

\section{Authors' Contribution}

HB conceptualized and designed the study, drafted the initial manuscript, critically reviewed the manuscript, supervised data collection and approved the final manuscript as submitted. GAM carried out the initial analyses, reviewed and revised the manuscript, and approved the final manuscript as submitted. MZ carried out the initial analyses, reviewed and revised the manuscript, and approved the final manuscript as submitted. MA designed the study and carried out the initial analyses, reviewed and revised the manuscript, and approved the final manuscript as submitted. FR designed the data collection instruments, and coordinated and supervised data collection at two of the four sites, critically reviewed the manuscript, and approved the final manuscript as submitted. All authors approved the final manuscript as submitted and agree to be accountable for all aspects of the work.

\section{Conflict of Interest Disclosures}

The authors declare that they have no conflicts of interests. The authors take full responsibility for the content and writing of this article.

\section{Ethical Statement}

The study was approved by the Ethics Committee of Mashhad University of Medical Sciences (Approval code: IR.MUMS. MEDICAL.REC.1397.53) followed by obtaining the consent from the parents of studied infants.

\section{Funding/Support}

The Vice-Chancellor for Research of Mashhad University of Medical Sciences sponsored this research.

\section{References}

1. Guglani L, Lakshminrusimha S, Ryan RM. Transient tachypnea of the newborn. Pediatr Rev. 2008;29(11).

2. Niisato $\mathrm{N}$, Ito $\mathrm{Y}$, Marunaka $\mathrm{Y}$. cAMP stimulates $\mathrm{Na}$ _transport in rat fetal pneumocyte: involvement of a PTK- but not a PKAdependent pathway. Am J Physiol. 1999;277(4):L72736. doi: 10.1152/ajplung.1999.277.4.L727.
3. Norlin A, Folkensson HG. $\mathrm{Ca}(2+)$-dependent stimulation of alveolar fluid clearance in near-term fetal guinea pigs. Am J Physiol Lung Cell Mol Physiol. 2002;282(4):L642-9. doi: 10.1152/ajplung.00417.2000.

4. O'Brodovich H, Hannam V, Seear M, Mullen JB. Amiloride impairs lung water clearance in newborn guinea pigs. J Appl Physiol (1985). 1990;68(4):1758-62. doi: 10.1152/ jappl.1990.68.4.1758.

5. Helve O, Janer C, Pitkanen O, Andersson S. Expression of the epithelial sodium channel in airway epithelium of newborn infants depends on gestational age. Pediatrics. 2007;120(6):1311-6. doi: 10.1542/peds.2007-0100.

6. Jain L, Eaton DC. Physiology of fetal lung fluid clearance and the effect of labor. Semin Perinatol. 2006;30(1):34-43. doi: 10.1053/j.semperi.2006.01.006.

7. Machado LU, Fiori HH, Baldisserotto M, Garcia PC, Vieira AC, Fiori RM. Surfactant deficiency in transient tachypnea of the newborn. J Pediatr. 2011;159(5):750-4. doi: 10.1016/j. jpeds.2011.04.023.

8. Greenough A. Transient tachypnea of newborn. In: Chernick V, Boat TF, Wilmott RW, Bush A, eds. Kendig's Disorders of the Respiratory Tract in Children. Philadelphia, Pa: Saunders Elsevier; 2006:325-6.

9. Konca C, Kahramaner Z, Bulbul M, Erdemir A, Tekin M, Ercan $S$, et al. Association between serum 25-hydroxyvitamin D levels and TTN. Horm Res Paediatr. 2014;81(6):397-401. doi: 10.1159/000358521.

10. Omran A, Mousa H, Abdalla MO, Zekry O. Maternal and neonatal vitamin $\mathrm{D}$ deficiency and transient tachypnea of the newborn in full term neonates. J Perinat Med. 2018;46(9):105760. doi: 10.1515/jpm-2017-0280.

11. Aytekin A. Comparison of Vitamin D levels between healthy individuals and cancer patients. EJMI. 2020;4(2):259-64.

12. Umar M, Sastry K, Chouchane A. Role of vitamin D beyond the skeletal function: A review of the molecular and clinical studies. Int J Mol Sci. 2018;19(6):1618. doi: 10.3390/ ijms19061618.

13. Fischer KD, Agrawal DK. Vitamin D regulating TGF-beta induced epithelial-mesenchymal transition. Respir Res. 2014;15(1):146. doi: 10.1186/s12931-014-0146-6.

14. Nguyen $M$, Guillozo $H$, Garabedian $M$, Balsan S. Lung as a possible additional target organ for vitamin $\mathrm{D}$ during fetal life in the rat. Biol Neonate. 1987;52(4):232-40. doi: 10.1159/000242714

15. Chen L, Wilson R, Bennett E, Zosky GR. Identification of vitamin D sensitive pathways during lung development. Respir Res. 2016;17:47. doi: 10.1186/s12931-016-0362-3.

16. Kovacs CS. Vitamin D in pregnancy and lactation: maternal, fetal, and neonatal outcomes from human and animal studies. Am J Clin Nutr. 2008;88(2):520S-8S. doi: 10.1093/ ajcn/88.2.520S.

17. Burris $\mathrm{HH}$, Rifas-Shiman SL, Camargo CA, Litonjua AA, Huh SY, Rich- Edwards JW, et al. Plasma 25-hydroxyvitamin $\mathrm{D}$ during pregnancy and small-for gestational age in black and white infants. Ann Epidemiol. 2012;22(8):581-6. doi: 10.1016/j.annepidem.2012.04.015.

18. Yang LR, Li H, Yang TY, Zhang T, Zhao RC. Relationship between vitamin $D$ deficiency and early-onset neonatal sepsis [in Chinese]. Zhongguo Dang Dai Er Ke Za Zhi. 2016;18(9):791-5.

19. Wayse V, Yousafzai A, Mogale K, Filteau S. Association of subclinical vitamin D deficiency with severe acute lower respiratory infection in Indian children under $5 \mathrm{y}$. Eur J Clin Nutr. 2004;58(4):563-7. doi: 10.1038/sj.ejcn.1601845

20. Boskabadi H, Zakerihamidi M, Faramarzi R. The vitamin D level in umbilical cord blood in premature infants with or without intra-ventricular hemorrhage: A cross-sectional study. Int J Reprod Biomed (Yazd). 2018;16(7):429-434. 
21. Boskabadi H, Maamori G, Khatami F, Faramarzi R. Serum level of vitamin $\mathrm{D}$ in preterm infants and its association with premature-related respiratory complications: a case-control study. Electron Physician. 2018;10(1):6208-6214. doi: 10.19082/6208. eCollection 2018 Jan.

22. Singh G, Sood R, Singh Narang G, Kaur Brar H, Kaur Bagga $\mathrm{H}$. Association of serum vitamin D levels and transient tachypnea of newborn: a case control study. J Perinat Med. . 2018;46(9):1057-60. doi: 10.1515/jpm-2017-0280.

23. Boskabadi H, Maamouri G, Hemmatipour A, Parvini Z, Ramazani A, Bagheri F. Comparison of serum vitamin D in the umbilical cord of survived with not survived premature infants. Iran J Pediatr. 2019;29(3):e84798.

24. Lee JM, Smith JR, Philipp BL, Chen TC, Mathieu J, Holick MF. Vitamin D deficiency in a healthy group of mothers and newborn infants. Clin Pediatr (Phila). 2007;46(1):42-4. doi: 10.1177/0009922806289311.

25. Bodnar LM, Simhan HN, Powers RW, Frank MP, Cooperstein E, Roberts JM. High prevalence of vitamin D insufficiency in black and white pregnant women residing in the northern United States and their neonates. J Nutr. 2007;137(2):44752. doi: 10.1093/jn/137.2.447.

26. Sachan A, Gupta R, Das V, Agarwal A, Awasthi PK, Bhatia V. High prevalence of vitamin $D$ deficiency among pregnant women and their newborns in northern India. Am J Clin Nutr. 2005;81(5):1060-4. doi: 10.1093/ajcn/81.5.1060.
27. Maghbooli Z, Hossein-Nezhad A, Shafaei AR, Karimi F, Madani FS, Larijani B. Vitamin D status in mothers and their newborns in Iran. BMC Pregnancy Childbirth. 2007;7:1. doi: 10.1186/1471-2393-7-1.

28. Lykkedegn S, Sorensen GL, Beck-Nielsen SS, Christesen HT. The impact of vitamin D on fetal and neonatal lung maturation. A systematic review. Am J Physiol Lung Cell Mol Physiol. 2015;308(7):L587-602.

29. Zosky GR, Berry LJ, Elliot JG, James AL, Gorman S, Hart PH. Vitamin $\mathrm{D}$ deficiency causes deficits in lung function and alters lung structure. Am J Respir Crit Care Med. 2011;183(10):133643.

30. Gatera VA, Abdulah R, Musfiroh I, Judistiani RT, Setiabudiawan B. Updates on the status of vitamin D as a risk factor for respiratory distress syndrome. Adv Pharmacol Sci. 2018;2018:8494816. doi: 10.1155/2018/8494816. eCollection 2018.

31. Dinlen N, Zenciroglu A, Beken S, Dursun A, Dilli D, Okumus N. Association of vitamin D deficiency with acute lower respiratory tract infections in newborns. J Matern Fetal Neonatal Med. 2016;29(6):928-32. doi: 10.3109/14767058.2015.1023710.

32. Belderbos ME, Houben ML, Wilbrink B, Lentjes E, Bloemen EM, Kimpen JLL, et al. Cord blood vitamin D deficiency is associated with respiratory syncytial virus bronchiolitis. Pediatrics. 2011;127:e1513-20. 